\title{
Pulse Oximetry
}

National Cancer Institute

\section{Source}

National Cancer Institute. Pulse Oximetry. NCI Thesaurus. Code C38085.

A non-invasive method that provides estimates of arterial oxyhemoglobin saturation by

utilizing selected wavelengths of light to determine the saturation of oxyhemoglobin. 